\title{
Study on Private Enterprises Participating in the "Belt and Road" construction: Taking Wenzhou as an Example
}

\author{
Mingwei Ni ${ }^{1, ~ a ~}$, Zhanao Wang ${ }^{2,3, ~ b, ~ * ~}$ \\ ${ }^{1}$ School of foreign languages and international trade, Wenzhou Business College, Zhejiang 325035, \\ China; \\ ${ }^{2}$ School of public affairs, Zhejiang University, Zhejiang 325035, China; \\ ${ }^{3}$ School of foreign languages and international trade, Wenzhou Business College, Zhejiang 325035, \\ China; \\ aa13806866876@qq.com, ${ }^{b}$ wzawhu@163.com
}

Keywords: The “Belt and Road”, Export trade, Wenzhou private enterprise.

Abstract: Under the initiative of "Belt and Road", private enterprises have become an important force in the process of economic construction. As the only coastal city where north and south economic zones meet, "Wenzhou model" has become a representative model of private economic development. This paper takes Wenzhou as an example to understand the current situation of private enterprises in Wenzhou participating in the "Belt and Road" from the aspects of total investment, and analyzes the characteristics of enterprises participating in the "Belt and Road" from the aspects of enterprise regional distribution and enterprise scale. Based on the interview with enterprises, this paper puts forward the product positioning, standard trade and other policy recommendations.

\section{The current situation of private enterprises in Wenzhou participating in The Belt and Road"}

Wenzhou, an open coastal city serving as an outpost for coastal defense, received little state investment during the period of planned economy. According to the data, the total state investment in Wenzhou was only 655 million yuan from 1949 to the following 32 years. Therefore, the people of Wenzhou only spontaneously formed the development model characterized by "small commodity, big market". However, although the Wenzhou economy has its own unique pattern, it benefits from the fact that it is the intersection of the Yangtze river delta and the western sea area along the southeast coast of China, and it is at the middle point of the coastline, the only coastal city where the two major economic zones of the north and south meet. This natural geographical position promotes Wenzhou enterprises to "go out". According to statistics bulletin, customs statistics of national economic and social development in Wenzhou, the industrial economic structure and the distribution of import and export trade in Wenzhou in 2008 are shown in table 1.

Given full play to geographical location advantages and accompanied by the improvement of external transport infrastructure in the 13th five-year plan period, Wenzhou has been actively guided to take the road of internationalization under the background of further opening up to the outside world, and has long been engaged in foreign economic cooperation. According to statistics of Wenzhou foreign trade and economic cooperation bureau, the overseas enterprises set up by private 
enterprises in Wenzhou cover more than 40 countries and regions, including Europe, America, Asia and Africa. The investment is mainly concentrated in southeast Asian countries, Russia, eastern Europe and a few western developed countries. The specific investment locations are shown in table 2:

Table 1 Statistics of Wenzhou industrial economy and import and export

\begin{tabular}{|c|c|c|c|c|c|}
\hline Business category & \multirow{2}{*}{$\begin{array}{c}\text { Unit number } \\
\text { (enterprise) }\end{array}$} & $\begin{array}{c}\text { Proportion } \\
(\%)\end{array}$ & $\begin{array}{c}\text { Actual performance } \\
\text { (Hundred million } \\
\text { yuan) }\end{array}$ & $\begin{array}{c}\text { Proportion } \\
(\%)\end{array}$ & $\begin{array}{c}\text { Actual } \\
\text { performance } \\
\text { (Hundred million } \\
\text { yuan) }\end{array}$ \\
\hline $\begin{array}{c}\text { State-owned and } \\
\text { collective } \\
\text { enterprises }\end{array}$ & 665 & 4.6 & 244.32 & 15.74 & 22.02 \\
\hline $\begin{array}{c}\text { overseas-invested } \\
\text { enterprises }\end{array}$ & 639 & 5.7 & 305.71 & 13.69 & 19.15 \\
\hline $\begin{array}{c}\text { The private } \\
\text { enterprise }\end{array}$ & 32216 & 70.20 & 3729.87 & 70.57 & 98.75 \\
\hline Individual business & 113939 & 19.5 & 1039.45 & & \\
\hline Totally & 147459 & 100 & 5319.35 & 100 & 139.92 \\
\hline
\end{tabular}

Data source: Wenzhou national economic and social development statistical bulletin and customs statisticsin 2008 1-12

Table 2 Regional distribution of Wenzhou overseas investment

\begin{tabular}{|c|c|c|c|}
\hline Investment & Number of Enterprises & Total Investment & Chinese investment \\
\hline The United States & 86 & 4680 & 4468 \\
\hline Europe and Russia & 228 & 15810 & 15462 \\
\hline Middle East and Africa & 142 & 15402 & 12344 \\
\hline Asia & 126 & 9172 & 8584 \\
\hline Australia and South America & 19 & 870 & 829 \\
\hline Other regions & 8 & 78 & 70 \\
\hline Totally & 609 & 46012 & 41757 \\
\hline
\end{tabular}

Data source: External investment statistics of Wenzhou foreign trade and economic cooperation bureau

In response to the construction of "The Belt and Road", by 2016, Wenzhou had 3 state-level foreign economic and trade cooperation zones and 1 provincial-level trade logistics park along the "The Belt and Road" in Uzbekistan, Russia and Vietnam, which is the most state-level regional city. There are nearly 228 enterprises in the four major parks, with an annual output value of about 2.2 billion US dollars, driving nearly 880 million us dollars in exports. At the same time, Wenzhou people have established 18 overseas commodity cities, 261 overseas marketing agencies, and set up an overseas marketing network connecting "The Belt and Road". Up to now, 688,000 Wenzhou people have set up businesses in 131 countries and regions, among which 380,000 are located in countries along the "The Belt and Road". Wenzhou gives full play to the advantages of Wenzhou people in the world, and strives to promote enterprises to "go out".

Among them, mainly the investment and trade with the ten ASEAN members, they are the destination countries with the largest issuance of "The Belt and Road" certificate of origin in Wenzhou. Issued by the customs data show that in the first half of 2018, Wenzhou exporter for all kinds of certificate of origin "The Belt and Road" national 24288, the amount of visa is $\$ 830$ million, including 9750 of the ASEAN free trade area preferential certificate of origin visa amount, the 
amount of visa is $\$ 390$ million, respectively "neighbourhood" all the way along the certificate of origin were $40.14 \%$ and $46.98 \%$ of the total.

\section{Features of Wenzhou private enterprises participating in the construction of "The Belt and Road"}

\subsection{Regional distribution characteristics of enterprise}

The private enterprises of Wenzhou participating in the construction of "The Belt and Road" mainly cover the Longwan county, Lucheng county, Ouhai county, Yueqing county, Ruian county, Yongjia county, Dongtou county, Pingyang county and Cangnan county of Wenzhou, and rarely involve the two underdeveloped regions of wenzhou, Taishun county and Wencheng county. The geomorphology of Wenzhou is a hilly area, dominated by mountainous areas within the territory, with the mountainous area as high as $78 \%$. Natural environment factors, such as large population and less land, poor resources and poor traffic conditions, have resulted in the imbalance of economic development in Wenzhou county. Moreover, with the improvement of the overall economic development level, this difference in economic development is still expanding. The specific economic development level of Wenzhou counties in 2004 is shown in table 3:

Table 3 Analysis of differences in economic development level of Wenzhou counties (2004)

\begin{tabular}{|c|c|}
\hline County & GDP Per Capita (Yuan) \\
\hline Longwan & 32625 \\
\hline Ouhai & 18652 \\
\hline Yueqing & 14072 \\
Ruian & 13463 \\
\hline Yongjia & 8230 \\
Dongtou & 8132 \\
Pingyang & 9309 \\
Cangnan & 7203 \\
\hline Wencheng & 3655 \\
Taishun & 3841 \\
\hline
\end{tabular}

Note 1: As Lucheng county is a downtown area, except for a few towns, most of the streets are non-economic independent accounting, so this table does not include Lucheng countyt.

\subsection{Enterprise scale and investment mode characteristics}

All the way to participate in the "The Belt and Road" of the construction of Wenzhou private enterprises in the development process step by step, in all parts of the country and even in the world for commercial activities such as investment or equity investment, private capital is growing, the family enterprise modernization, is completely different from the original of the inherent concept of "Wenzhou mode". And transportation costs generally smaller scale, technology content, these enterprises gradually developed into a modern joint-stock enterprise or a listed company. Private enterprise industry continues to develop to scale, $\mathrm{Yu}$ Guansheng thinks that the larger private enterprises are more inclined to direct investment. The investment mode of enterprises is still dominated by overseas investment modes such as new establishment, merger and acquisition, capital increase, etc., but other investment modes gradually emerge, such as emerging investment modes, overseas bond issuance and financing, and the investment modes are increasingly diversified. 


\subsection{Product type characteristics of enterprise}

All the way to participate in the "The Belt and Road" of the construction of the Wenzhou business industry is very diverse, the main product categories are mechanical and electronic products, seven class of traditional labor dense type products, high-tech products, etc., such as lighters, shoes and other light industrial products covered a major share in the international market, the commodity from the traditional to the high quality product development.

\section{Factors influencing Wenzhou enterprises' participation in The Belt and Road}

\subsection{Economic factors}

\subsubsection{Product standard and market demand}

An enterprise should position its own products according to its own technology. The significance of participating in "The Belt and Road" is to deepen the depth and breadth of trade with countries along the belt and road. Under the background of the construction of "The Belt and Road" initiative, commodity trade should conform to the technological and brand added value of the products pursued by the other side, and it is not just the cheap and good in the past. Therefore, the product standard of the enterprise plays a decisive role in the improvement of the enterprise's foreign trade and market competitiveness. The enterprise needs to determine the exporting country according to the actual quality of the product, because different countries have different standards for the same product.

\subsubsection{Labor force level and industry type}

There is a shortage of internationalized talents. It is difficult to find interdisciplinary talents who are familiar with the two countries' cultures, learn international operation and operation, understand management and trust. It is difficult to find specialized talents like business, law, finance, intellectual property and even language, which is a big obstacle for enterprises to invest overseas. Secondly, operate on the low end. Most private enterprises participate in the construction of "The Belt and Road" without key core technologies and high-end products, or form an international brand with recognition. At present, the investment is still mainly in labor-intensive industries, with less capital intensive investment and less investment in high-tech.

\subsubsection{Culltural differences and risks arise}

Although the "The Belt and Road" initiative has become a world consensus, there are still many risk problems in the construction process of "The Belt and Road". The first is political risk: most of the countries along the "The Belt and Road" are small and medium developing countries with frequent political instability, frequent government changes and easy policy changes. Secondly, economic risks: due to insufficient research on projects and national laws and regulations, enterprises may lose money even if they take capital and technology out and set up factories. And religious and cultural risk: national culture, customs and habits are different, in the face of such risks, the private enterprise in go out and participate in all the way area construction process, to abide by the "neighbourhood" all the way along the national laws and policies and regulations, as well as traditional religious culture conditions, at the lowest cost of risk aversion to obtain maximum investment operating earnings. Although full of all kinds of problems and risks, everything has two sides. Risks and opportunities complement each other, and it is worth for enterprises to make every effort to resolve them and win greater strategic initiative. 


\subsection{Institutional factors}

The guarantee of system and the system of law have great influence on enterprises' participation in The Belt and Road. It is generally recognized that the trade and investment of enterprises will flow to countries and regions with good institutional guarantee and perfect legal system, which is a reaction of the instinct of capital to seek advantages and avoid disadvantages. When both countries in trade have good systems and perfect service platforms, enterprises can get more comprehensive support and guidance in information consultation, risk assessment, dispute settlement and other aspects, which has a good role in promoting the achievement of trade cooperation, further promoting enterprises to "go out" and strengthening the guidance of the organization.

The most direct impact on the private enterprises investing overseas in Wenzhou is the overseas export tax refund system. After the reform of the export tax refund system, it is stipulated that the exported goods can still be reported for export tax refund within the reporting period of each value-added tax before April 30 of the next year. This rectification is mainly aimed at solving the problems such as the development of current economic situation and the adjustment of tax refund policy documents, scattered regulations and inconvenient management, which is conducive to stabilizing foreign trade export, alleviating the burden of enterprises, simplifying tax refund declaration procedures, and facilitating the systematic and accurate understanding and implementation of export tax refund policies by both sides.

\section{Participate in the impact of "The Belt and Road" initiative on the performance of Wenzhou enterprises -- interview analysis}

In order to better understand the situation of private enterprises in Wenzhou participating in "The Belt and Road", we conducted a brief interview on some private enterprises in Wenzhou Ouhai county economic development zone in the day of May 16, 2018, on issues such as the impact of One Belt And Road initiative on enterprises. Wenzhou Haizhou Packaging Machinery Co., LTD., founded in 2009, mainly deals in packaging machinery (assembly line, packaging, label, code, etc.) and serves global customers. Most of the customers are from neighboring southeast Asian countries. Zhongheng International Trade Co., LTD. Founded in 2011, mainly deals with freight forwarders of small packages, logistics of cross-border e-commerce, and services of Germany, Britain and Hungary.

\subsection{The impact of the The Belt and Road initiative on businesses}

Economic globalization is the overall trend of the market, not only driven by "The Belt and Road". Nowadays, the Internet is developed, information is transparent, and there are many international platforms, such as Alibaba, universal, etc. Besides, B2B platforms are also developed, making it easier for customers and merchants to get in touch. And the popularity of English, B2B, B2C, various exhibitions, than different regions such as Thailand, Vietnam, Indonesia, the United States and China's Canton fair. The company's foreign trade is responding to the construction of "The Belt and Road" while the demand of the economic market keeps expanding.

As a result of the construction of "The Belt and Road", the information between sellers and dealers, dealers and terminal customers is more transparent, which makes it easier for terminal customers to understand the price, so dealers have less profit space. Therefore, in order to reduce the cost, the importer has the intention of establishing a factory in a closer place, but the production enterprise as the source will not be affected. In addition, service enterprises cannot be any party of the buyer and seller. The customer source has a special sales department to contact, and the chamber of commerce 
has not yet provided clear help on the customer source.

\subsection{Influence of government on enterprises}

The government will provide subsidies according to the scale of the company's participation. In the past, the government would subsidize the site leasing. In addition, Internet platforms also have subsidies. The current form of subsidies is unclear, possibly because the government responsible for the relevant work of the administrative staff to replace. But businesses still want more government support, such as information on all sides.

\section{Wenzhou enterprises to participate in the policy recommendations of The Belt and Road}

\subsection{Positioning product standards and adapting to market needs}

Wenzhou enterprises currently involved in the countries and regions of area is limited, mainly concentrated in the southeast Asian countries, so the enterprises should learn more about the market demand, in other countries to actively participate in all kinds of exhibitions at home and abroad, understand the international standard, the demand of the international market, product production specialization, on the one hand, the introduction of advanced equipment and technology, improve product quality, actively develop new production. On the other hand, it can better locate the position of enterprise products, which countries and regions are suitable for, and better define the general direction of trade.

\subsection{Expand information channels and enrich investment models}

Wenzhou has a single way of participating in overseas investment, most of which is based on direct investment. There are few other ways, such as foreign mergers and acquisitions, financing and leasing, and the source is single. Therefore, we should vigorously carry out the project of "Merchants Regression", make full use of the advantages of overseas Chinese resources, and actively promote the return investment and investigation of the group. We will support leading enterprises and small and medium-sized enterprises with mature conditions to "go out" to establish production bases, research and development institutions, design centers, marketing networks, introduce foreign capital, and conduct resource development and cooperation. We will also support and encourage enterprises to acquire technologies, brands, sales networks and resource channels through cross-border mergers and acquisitions, integrate international quality resources, accelerate the global layout of value chains and supply chains, foster a number of local Wenzhou multinationals and well-known brands, and speed up the orderly expansion of competitive industries abroad.

\subsection{Regulate trade rules and respect cultural differences}

The enterprise standardizes its overseas operation, abides by the laws and regulations of the country where it is located, respects local culture, religion and customs, and safeguards the legitimate rights and interests of its employees. It is the business direction of modern enterprises to achieve the institutionalization, informatization and internationalization of management. The development of private enterprises in Wenzhou has gone through the process of transforming from family type, shareholding cooperative system, group company to shareholding system.

At present, most private enterprises in Wenzhou have entered the stage of shareholding reform, but there are still individual industrial households and joint-stock cooperative enterprises. It is not scientific to convert all of them into the corporate system in the near stage. Modern market economy 
does not exclude traditional enterprise system. However, they should also have a scientific and systematic strategic management ability, grasp the inherent law of enterprise growth and the uncertainty of market competition, summarize and refine their effective market experience and management skills, and improve to a theoretical level to guide enterprise management.

\section{Acknowledgement}

This paper was supported by the research project of students from Wenzhou Business School (Wenzhou participates in the current situation, problems and countermeasures of "The Belt and Road"), Wenzhou Social Science Planning Projects (Research on Carrier Function, Agglomeration Effects and Improvement Approach of Wenzhou Overseas Economic and Trade Cooperation Zones, project no.18wsk229) and China Postdoctoral Science Foundation (Studies on the Evolution Rules and Policies of the Asia-pacific Multilateral FTA from the Perspective of Relative Gains, project no.2017M611965)

\section{References}

[1] Outline of the 13th five-year plan for national economic and social development [J]. Occupational technology education,2017(03):69. (in Chinese)

[2] Pan Shaoyong. Analysis on the status, motivation and strategy of Wenzhou enterprises' fdi [D]. Jilin university,2010. (in Chinese)

[3] Xiejian. Comprehensive evaluation and difference analysis of Wenzhou county economic development level [J]. Journal of Wenzhou University,2006(06):4-9. (in Chinese)

[4] Yu Guansheng. Internal influencing factors of foreign direct investment decision-making of private enterprises -- an empirical study based on wenzhou micro-level enterprise data [J]. Journal of Beijing technology and business university (social science edition),2015(04):46-52. (in Chinese)

[5] Cheng Sunpeng. 'all the way along the construction under the background of Wenzhou standardization work path exploration [J]. China standardization, 2017 (in Chinese)

[6] Jiakang. The Belt and Road how to win more [J]. Economy,2017(17) (in Chinese)

[7] Zhangwen. The state supports small and medium-sized enterprises to participate in "The Belt and Road" construction, the ministry of industry and information technology and the China council for the promotion of international trade jointly issued the notice on carrying out special action to support small and medium-sized enterprises to participate in "The Belt and Road" construction [J]. China building metal structure,2017(10). (in Chinese)

[8] Xiaoying. New adjustment of export tax rebate for Wenzhou export enterprises benefited [N]. China apparel news,2012-07-20(A06). (in Chinese)

[9] ge Dan, wu li. Analysis of foreign investment and overseas investment in wenzhou and its countermeasures [J]. China business review,2017(6):67-68. (in Chinese)

[10] Liu Xunsheng. Constraints and breakthroughs in the development of private enterprises in Wenzhou [J]. Journal of Wenzhou University,2005(01):13-19. (in Chinese)

[11] Xu Yachun. Analysis of cultural characteristics and causes of private enterprises in Wenzhou [J]. Occupational time and space,2008(05):26-27. (in Chinese)

[12] Zhang Qiming. Marketing innovation: the inevitable choice of winning the competition of Wenzhou private enterprises [J]. Journal of Wenzhou University,2002(01):10-14. (in Chinese)

[13] Qiping. Study on China's private enterprise integrity system [D]. Jilin university,2010. (in Chinese)

[14] Zhou Linzi. Wenzhou actively participated in the construction of "The Belt and Road" [N]. Zhejiang daily,2017-08-21(004). (in Chinese)

[15] Yelan. "golden key" for enterprises to explore international market with certificate of origin [N]. China times,2018-07-09(002). (in Chinese)

[16] Tian Ruzhu. Private enterprises participate in "The Belt and Road" to resolve risks [N]. Economic information daily,2017-08-16(008). (in Chinese) 